\title{
SOBRE HERMETISMO Y CONFESIÓN
}

\author{
LUIS BELTRÁN ALMERÍA \\ Universidad de Zaragoza
}

Se cumplen ahora veinte años de la publicación de Palomar, quizá la más original obra de Italo Calvino. La bibliografía sobre esta obra es ya abundante pero, como suele ser frecuente, se ocupa con preferencia de aspectos secundarios o utiliza la obra para ilustrar a conveniencia tendencias críticas de moda. Me voy a ocupar aquí de su dimensión testamentaria, teórica, universal.

Por varias razones Palomar es una obra desconcertante y, a un tiempo, transparente. Desconcertante por su organización ternaria: tres secciones que se componen de otros tres capítulos cada una que constan, a su vez, de tres epígrafes, todos de dimensiones parejas. Y semejante orden y rigor matemáticos sirven para encauzar el desorden de una vida o, mejor, de las lecciones de una vida. Los temas de esos veintisiete apartados recorren todo tipo de cuestiones, desde la observación de los astros al zoo, pasando por el césped o la charcutería. Pero, tras esta disposición y exposición desconcertantes, se puede apreciar un propósito transparente: la confesión de una vida. Palomar es una confesión que no cuenta una vida, en el sentido de relatar una biografía. Se limita a cumplir una tarea más sutil -y quizá más inteligente - la tarea de ubicar una nueva forma de reconciliación con la vida, una forma que se sitúa más allá del individualismo y su sujeto. Y quizá por eso este pequeño libro sea un gran libro: abre las puertas a una nueva forma de ser persona, una forma distinta de la habitual en la era moderna, que ha consistido en ser individuo, esto es, sujeto de acciones y omisiones, de pasiones y afectos, protagonista y espectador.

Quizá convenga que empecemos por explicar cómo una obra puede ser a la vez una confesión, como las famosas Confesiones de San Agustín y Rousseau, y no contener - entre otras cosas- el relato de una vida. La solución a este aparente enigma es que la materia que se confiesa en Palomar no es algo individual sino de alcance superior: generacional o quizá suprageneracional, una dimensión para la que no encuentro la palabra precisa y que, en su defecto, llamaré histórica. También hay un segundo aspecto que abordaré cuando hayamos alcanzado una explicación suficiente del primero.

Rlit, LXV, 130 (2003), 533-538 


\section{LA CONFESIÓN}

El motor que ha llevado a diversos autores a componer confesiones responde a un principio moral. Una persona confiesa cuando es consciente de la falta de coincidencia entre su pasado y su presente. La fractura entre los dos estados de conciencia es un factor de inestabilidad que quien confiesa trata de corregir aferrándose a un nuevo centro, a un nuevo punto de equilibrio, en la mayoría de los casos sostenido por fuerzas poderosas -hoy, la opinión pública- Las peores confesiones escamotean esa fractura, justificando o falseando el pasado, esto es, tratan de ocultar las dimensiones de la dislocación aparentando que no ha habido tal. Mejor consideración requieren las confesiones que asumen el conflicto entre el pasado y el presente, asumen la responsabilidad que se deriva de ese conflicto y presentan argumentos que tratan de clarificar, comprender los hechos y probar la asimilación de la responsabilidad. Pero aún quedan un tercer grupo de confesiones, aquellas que resultan imprescindibles para la historia de la literatura universal y para la historia cultural misma. Son las confesiones que expresan una ruptura de alcance histórico o, para ser más preciso, el tipo de rupturas que se producen en el tránsito entre dos épocas. Tanto San Agustín como Rousseau ilustran este fenómeno. San Agustín da cuenta de la irrupción en el mundo de la Antigüedad tardía de un nuevo dogmatismo, que preludia el dogmatismo teocrático medieval e inaugura culturalmente el imperialismo cristiano. Rousseau anuncia el individualismo. $\mathrm{Su}$ conducta resulta escandalosa para la sociedad francesa de mediados del XVIII, pero se apoya en el ascenso irresistible de la ideología de lo que hoy llamamos modernidad. Agustín ve como pecaminosa su conducta anterior y asume un nuevo código. Rousseau justifica sus pecados -esos cinco hijos abandonados en la inclusa al día siguiente de nacer- porque tiene su propio código individual. Ese escalón histórico que Agustín y Rousseau suben es lo que hace grandes sus confesiones. Calvino se encuentra en esa misma situación. Si Agustín renuncia a su yo en virtud del dogma cristiano y Rousseau rompe con todo dogma que limite su ego, en el caso del señor Palomar estamos ante una doble renuncia o superación del dogma - laico- y del ego. En otras palabras, la confesión de Calvino supone la ruptura con el individualismo y la presencia de una nueva forma de ser/estar en el mundo. Trataré de explicar esto.

El señor Palomar nos confiesa su padecimiento y su dificultad para relacionarse con el prójimo (146) ${ }^{1}$. No se trata sólo de un sufrimiento en el terreno de las relaciones personales - aunque también lo es- sino de una

\footnotetext{
${ }^{1}$ Los números entre paréntesis hacen referencia a la paginación de la traducción de Aurora Bernárdez, publicada por Círculo de Lectores, Barcelona, 2000.
} 
relación problemática con el mundo. Ese malestar en el mundo parece tener su origen en la renuncia a una actitud idealista respecto al mundo: «hubo una época en que su regla era esta: primero construir en su mente un modelo, el más perfecto, lógico, geométrico posible; segundo, verificar si el modelo se adapta a los casos prácticos observables en la experiencia; tercero, aportar las correcciones necesarias para que modelo y realidad coincidan» (136). Este idealismo ha sido el espíritu dominante en la izquierda europea durante buena parte del siglo $\mathrm{Xx}$, al quedar atrás el dogmatismo burocrático que encarnó el comunismo oficial. El testimonio del señor Palomar consiste en la constatación del fracaso de ese método-modelo. Modelar - dice- es programar un sistema de poder, y del poder conviene esperar siempre lo peor. Lo que le interesa a Palomar es lo que sucede a pesar del poder: «la forma que la sociedad va adoptando lentamente, silenciosamente, anónimamente, en los hábitós, en el modo de pensar y de hacer, en la escala de valores» (140). Esta posición lleva al viejo idealista a una forma nueva de escepticismo, de silencio. Incluso los remedios a los males del mundo pueden causar otros males, quizá peores, en manos de reformadores iluminados, tal vez ineptos, tal vez prevaricadores o, incluso, ambas cosas al mismo tiempo. De ahí que la única salida sea «mantener sus convicciones en estado fluido, verificarlas caso por caso y convertirlas en la regla implícita del propio comportamiento cotidiano, en el hacer o en el no hacer, en el elegir o en el excluir, en el hablar o en el callar» (141).

He llamado a este comportamiento nueva forma de escepticismo. Quizá habría que decir falso escepticismo. El mismo señor Palomar no se conforma con esa renuncia al modelo ideal, único o complejo, y prosigue su investigación universal buscando «aplicar esa sabiduría cósmica a la relación con los semejantes» (148). Esa búsqueda es la confesión que contiene este libro. No supone una renuncia a la búsqueda de la verdad o de una escala de valores - por utilizar su propia expresión - sino una nueva búsqueda, una investigación abierta $\mathrm{y}$, en parte, contradictoria. Porque el único momento conclusivo al que llega Palomar constata que el universo es «el espejo donde podemos contemplar sólo lo que hayamos aprendido a conocer en nosotros» (150). Lo que busca Palomar en el cosmos es un orden, como siglos antes lo buscó San Agustín («Contempla el cielo, la tierra y el mar y todo cuanto hay en ellos ... Todas las cosas tienen su belleza, porque tienen su número: quítaselo y no quedará nada», De libero arbitrio II, XVI, 42). Casi lo podría firmar Calvino. Pero si atendemos un poco más veremos que a Calvino no le interesa en realidad la belleza universal (y menos como manifestación de la existencia de Dios), sino otra cosa distinta: las enormes posibilidades de nuevas simetrías, combinaciones, apareamientos que permite la disgregación del orden del mundo (129). En otras palabras, le interesa la norma oculta en lo fondo de lo existente en la medida en que es el motivo de esperanza en la salvación del género humano. Quizá en 
expresión teórica, que el propio Calvino elude, podría decirse que el desorden es la esperanza en un nuevo orden más complejo y más profundo. Calvino ilustra esa idea con la anécdota de la pantufla desparejada (3.1.3).

\section{EL HERMETISMO}

Y este aspecto contradictorio con la doctrina de la contemplación agustiniana nos lleva al segundo tema que anunciaba casi al comienzo de este artículo: el hermetismo. Calvino reúne, como autor, dos estéticas que no se reconcilian fácilmente: el humorismo y el hermetismo. El humor de Calvino es fácilmente observable a lo largo de todo el libro. El señor Palomar es una figura que permite el distanciamiento y la ironía respecto a las propias convicciones de Calvino, incluso se reviste de los atributos del tonto, del despistado y, en algún momento, despierta sospechas acerca de su estado mental - por ejemplo, cuando observa los astros en la playa-. El señor Palomar no es un personaje sino una figura para la autoparodia, la ironía moderna, como suelen ser las creaciones de Calvino. Expresa esta figura el método artístico que le permite situarse más allá del individualismo. Nada en esta obra es narcisista, que suele ser una de las formas estéticas más frecuentes del indivídualismo.

Pero ahora me interesa más la otra dimensión estética de Palomar, su hermetismo. Para empezar, he de señalar que este es un libro en apariencia mucho menos hermético que otros de Calvino, como Las ciudades invisibles. Pero si nos fijamos con algo más de detenimiento veremos en esta obra el perfil clásico del arte hermético. En primer lugar, la disposición de esas meditaciones es hermética porque sólo al final podemos percibir claramente que estamos ante una confesión o, quizá mejor, ante un testamento intelectual. El autor - en otro rasgo de humor - juega con el lector proponiéndole variados y curiosos temas y sólo paso a paso va destilando con cuentagotas su pensamiento a partir de las percepciones alcanzadas. En segundo lugar, esta obra persigue un único objetivo: aproximarse a la norma oculta de lo existente (114) en la medida en que es el motivo de la salvación del género humano (73). He reunido en esta frase dos conceptos que aparecen por separado en el escrito de Calvino, pero cuya conexión es esencial para comprenderlo. El hermetismo se mueve hacia un fin: alcanzar la salvación. Las claves para encontrarla están ocultas y sólo son reveladas a los iniciados. En este caso el iluminado Palomar pone en práctica una nueva forma de ver (la forma de ver descrita en el epígrafe 3.1.1 «El mundo mira al mundo»).

Acerca de la salvación Calvino-Palomar nos dice que ha llegado tarde a comprender que «reside en aplicarse a las cosas que están ahí» (73). Esta actitud de atención a lo inmediato es lo contrario de la impaciencia juve- 
nil y el voluntarismo («tratar siempre de hacer algo un poco más allá de los propios medios», 81). Este giro puede comprenderse en primera instancia como un giro generacional. La generación revolucionaria de la posguerra europea es, pasada la efervescencia del 68, una generación integrada, reconciliada. Pero ésta sería una lectura superficial. En el espíritu del senor Palomar alienta todavía una actitud rebelde, trascendente y trasgresora, aunque el objeto de la trasgresión ya no sea la esfera de lo político sino esa otra que está más allá de lo político, del poder y para la que CalvinoPalomar parece no encontrar un término adecuado. Quizá la mejor forma de definir esa segunda esfera sea la de un nuevo pensamiento, más allá del individualismo - que sólo es capaz de ver la esfera del poder-.

Pero hay todavía una última cuestión que emana de la faz hermética de Palomar. Hemos vuelto en el párrafo anterior a la cuestión generacional que, a mi juicio, fundamenta el testimonio de Calvino. He señalado que en los casos más notables la confesión - en cuanto género literario- alcanza su mayor grado de significación en la encrucijada entre dos épocas. En el caso de Calvino y de nuestra época eso significaría el tránsito del individualismo a otra forma de pensar, sin duda superior, capaz de asimilar un grado de integración del universo y la humanidad, y de conciliación de esta consigo misma. En ciertas regiones de la cultura actual ese grado superior de comunicación humana es conocido como dialogismo, construir un diálogo entre los que deben ser un diálogo - lo que incluye la naturaleza-, según un conocido lema de Gadamer. Y la pregunta ahora debe ser: ¿es Calvino un aventajado heraldo del dialogismo, como Rousseau lo fue del individualismo? Llegados a este punto, conviene que nos impregnemos de una buena dosis de espíritu calviniano para respondernos negativamente. La edad del individualismo no ha concluido. Pese a las secuelas - cada vez más graves- y al alto coste en posibilidades de expansión de la humanidad a todos los niveles, todavía - y no sabemos por cuánto tiempoel individualismo tiene tareas que cumplir y sigue renovando sus formas y contenidos. El propio Calvino es consciente de ello, pese a que no llegue a verbalizarlo. La prueba de esa conciencia es su hermetismo y su ironía. Este hermetismo irónico es la forma estética de un pensamiento que sabe que no ha llegado su hora y que no sabe cuánto ha de esperar. Al menos, frente al hermetismo clásico, sabe que esa hora ha de llegar alguna vez, pero ha aprendido a liberarse de la impaciencia juvenil y a entender (sólo en teoría) que la única salvación reside en aplicarse a las cosas que están ahí. Ese es el testamento de Calvino-Palomar. Es un testamento que, más allá de su significación en el canon de la literatura italiana, significa, como hemos visto, en el marco de la cultura universal. 


\section{RESUMEN}

Sobre hermetismo y confesión, por Luis Beltrán Almería.

Palomar de Italo Calvino es una obra de tema y estructura muy originales. Se trata de una confesión, cuyo autor sólo cuenta unas anécdotas de apariencia insignificante. Y, sin embargo, es una profunda y trascendental confesión. El secreto radica en el humorismo hermético de Calvino y en su superación del individualismo.

Palabras clave: Calvino, Palomar, confesión, hermetismo, individualismo.

\section{SUMMARY}

Palomar by Italo Calvino is a work with a very original theme and structure. It deals with a confession whose author narrates only some «trivial» anecdotes. However it is a deep and «trascendent» confession. The secret lies in the hermetic humor and in what goes beyond individualism.

Key words: Calvino, Palomar, confession, hermetism, individualism. 